\title{
Internal and External Cartel Stability: Numerical Solutions
}

\author{
Christos Papahristodoulou ${ }^{1}$ (D)
}

Accepted: 27 April 2018 / Published online: 4 May 2018

(C) The Author(s) 2018

\begin{abstract}
The size of imperfect cartels, i.e. with participating (k-firms) and nonparticipating or fringe ( $\mathrm{j}$-firms), has been investigated by some researchers since early 1980s. Most papers, based on simple cost and demand functions, have proposed various conditions to find the optimal number of k-firms. Recently, other researchers have conducted numerical simulations or used an analytic approach to determine the size of stable cartels. In this paper, I investigate two standard models, with additional parameters in demand and cost functions. In the first model the cartel faces $\mathrm{j}$ competitive firms, while in the second model the cartel is the Stackelberg leader and the j-firms are Cournot followers. In the second model, the entry to and exit from cartel are formulated as integer non-linear programming, using some parameter bounds. Contrary to other studies who relied on simplified functions and found exact algebraic conditions, Mathematica fails to provide such conditions. It does provide though global numerical solutions. In the first model, irrespectively of the number of firms, the optimal number of k-firms is always three. In the second model, the number of k-firms is moderate higher, but lower than other studies find.
\end{abstract}

Keywords Cartel and fringe firms · Internal and external stability · Global optimum

\section{Introduction}

Imperfect cartels is a market structure where the cartel participating firms compete with other fringe firms. A well-known example is oil. The OPEC is the world's largest cartel. Moreover, it is an imperfect cartel, because its 13 members' market share for

\footnotetext{
Christos Papahristodoulou

christos.papahristodoulou@mdh.se

1 School of Business, Society and Engineering, Mälardalen University, Västerås, Sweden
} 
oil in 2015 was almost 36\% (OPEC 2016). There are at least 50 countries (like the US, Russia and Norway) that account for the remaining 64\%. If the market shares or the proportion of OPEC/non-OPEC share remain stable, one can conclude that this imperfect cartel is stable. Would it be better if one OPEC country left the cartel or if Russia joined it? Still there are more countries with proven oil reserves that might start production. What will happen to stability if a new oil-producing country enters the world market as a fringe, or if it is welcomed by the OPEC?

The stability of imperfect cartel has a long research history. Selten (1973) was the first to argue that four firms in a market are a few while six are too many. Ten years later, D'Aspremont et al. (1983), modelled the behavior of fringe firms ( $j$-firms) as price-takers. Donsimoni et al. (1986) and Daskin (1989), based on D'Aspremont et al. (1983), showed that stable cartels exist with a rather small number of firms and when the number of firms in the market increases, the relative size of cartel firms ( $k$-firms) decreases. Shaffer (1995), assuming constant marginal costs, was the first to introduce the Cournot behavior of the $j$-firms as followers and the $k$-firms as the price-leaders. The conditions she proposed for internally stable cartels for $n \geq 4$, are $k \leq \frac{n}{2}+1$, for even $n$, respectively $k \leq \frac{n+1}{2}+1$, for odd $n$, and reverse bounds for externally stable cartels. It is noteworthy, as Shaffer argues, that the values of parameters do not influence these conditions. A similar model was used by Escrihuela-Villar (2008), arguing that, in stable cartels, the number of cartel firms with $n \geq 4$ is independent from the parameters and is determined, either by $\frac{1}{4}(1+3 n-\sqrt{(n-2) n-7}$, or by the same condition plus one. Konishi and Lin (1999) modified Shaffer's model by assuming quadratic cost function, without a fixed part, and setting the slope of demand curve equal to unit. Due to algebra complexity, they conducted numerical simulations. $\mathrm{Zu}$ et al. (2012), followed Konishi and Lin and provided an analytic approach to determine the size of stable cartels. Their estimates are similar to Konishi and Lin, or slightly larger, especially when the cost parameter increases. They also concluded that stable cartels will consist of relatively fewer firms when the cost parameter rises. On the other hand, they questioned the uniqueness of the stable cartel, argued by Konishi and Lin.

In this paper I present two general models. The first model is based on D'Aspremont et al. (1983), where the cartel faces $j$-competitive firms. The second model is based on Shaffer (1995) and Konishi and Lin (1999), where the $k$-firms are the Stackelberg leader while the $j$-firms behave as Cournot followers. The models are more general in a sense that they include two more parameters, one for the slope of demand and another for the slope of the marginal cost function, including an intercept.

Precisely as these referred models, both are single period models, where firms make entry to/exit from cartel decisions by observing their ex-ante profits as $j$ - or $k$-firms, with their ex-post profits as $k$ - or $j$-firms. It is assumed also that tensions, cheating and monitoring the $k$-firms is independent from its size. All $k$-firms comply with their optimal production (or price) and their commitment to co-ordination will not be jeopardized, even if they are granted amnesty (i.e. by applying the discriminatory leniency policy) to those who become "whistleblowers", as Clemens and Rau (2014) find. In both models it is assumed that there is no a ringleader among the $k$-firms to coordinate the cartel and ensure its success. In fact, according to Bos and Wandschneider (2011) 
there might exist more than one ringleaders and prices can be higher without a cartel ringleader. Obviously, if the leniency policy is successful, as the European Commission (2017) argues, the theoretically optimal number of $k$-firms should be lower and in best case the cartel will be abolished. Notice though that the OPEC example above is not appropriate for anti-trust policies, because OPEC's activities are protected by U.S. foreign trade laws.

Since I am interested only in integer firms, the algebra complexity will be more tedious than, for instance, in the Konishi and Lin model. Consequently, it would be extremely difficult, if possible, to obtain general, integer stability conditions. To my help I relied on two powerful Mathematica functions "Reduce" and "NMinimize". "Reduce" finds all possible conditions that satisfy the objective function and "NMinimize" obtains global constrained ( $\mathrm{min}$ ) numerical values.

The paper is organized as follows. Section 2 derives the quantities, prices and profits in both models; Sect. 3 presents some numerical estimates of cartel stability for both models; Sect. 4 presents the formulation for cartel stability, while the estimates are shown and compared in Sect. 5. Finally Sect. 6 concludes the paper with some policy implications.

\section{The Model}

Following the notation of Carlton and Perloff (2015), it is assumed that there is a fixed number of firms, $j+k=n$, with $j=$ fringe and $k=$ cartel firms, producing a homogeneous product $q$. All firms maximize profits in a timeless environment. The $j$-firms can join the cartel, and the $k$-firms can leave the cartel and become fringe, if they find it profitable. The cost and demand functions are also static. All firms' marginal costs are, $M C=d+e q$, while the linear market demand function is given by $Q=\alpha-\beta P$, with $Q=Q_{c a r t}+Q_{f r} ; Q_{c a r t}=k q_{c a r t}, Q_{f r}=j q_{f r}$.

\subsection{Model 1: The $j$-Firms are Price Takers}

The residual demand for the k-firms is defined as: $Q_{\text {cart }}=(\alpha-\beta P)-\frac{j(P-d)}{e}$, where $\frac{j(P-d)}{e}=j q_{f r}$, determined by assuming that all j-firms will produce where $M C=P$. Solving the residual demand for $\mathrm{P}$ we get $P=\frac{d j+e \alpha-e Q_{\text {cart }}}{j+e \beta}$.

By maximizing the profit for cartel, the first order conditions will give the following total cartel quantity and price:

$$
\begin{gathered}
Q_{c a r t}=\frac{k(\alpha-d \beta)}{j+2 k+e \beta} \\
P_{c a r t}=\frac{d j+e \alpha-\frac{e k(\alpha-d \beta)}{j+2 k+e \beta}}{j+e \beta}
\end{gathered}
$$

Consequently, all the price takers $j$-firms will produce 


$$
Q_{f r}=\frac{j(\alpha-d \beta)(j+k+e \beta)}{(j+e \beta)(j+2 k+e \beta)} .
$$

Since the total production is given by the sum of $Q_{\text {cart }}+Q_{f r}$, the individual production is given by dividing (1.1) and (1.3) by their respective number $k$ and $j$. Finally, the individual profits are:

$$
\begin{aligned}
& \pi_{c a r t}=\frac{e(\alpha-d \beta)^{2}}{2(j+e \beta)(j+2 k+e \beta)} \\
& \pi_{f r}=\frac{e(\alpha-d \beta)^{2}(j+k+e \beta)^{2}}{2(j+e \beta)^{2}(j+2 k+e \beta)^{2}}
\end{aligned}
$$

Needless to say that if $j=0,(1.1),(1.2)$ and (1.4) give the total production of perfect cartel, the price and the individual profits of a $k$-firm. Similarly if $k=0,(1.3)$, (1.2) and (1.5) give the total production, price and profits for perfect completion. In general, if we exclude the degenerate case where a single firm is not defined as cartel, we can set the lower bound for a cartel, when $k \geq 2$.

\subsection{Model 2: The $k$-Firms are the Stackelberg Leader and $\boldsymbol{j}$-Firms are Cournot Followers}

In Model 2, in accordance with other researchers, I work with the inverse demand function $P=a-b Q$, because it is easier to handle its residual demand. ${ }^{1}$

The follower's profit is defined as

$$
\pi_{f}=\left(a-b\left(Q_{c a r}+Q_{f}+q_{f}\right)\right) q_{f}-d q_{f}-\frac{e q_{f}^{2}}{2}, \quad \text { where } Q_{f}=(j-1) q_{f} \text { and } Q_{c a r}=k q_{c a r} .
$$

The first order condition gives the reaction function $q_{f}=\frac{a-d-b Q_{\mathrm{car}}-b Q_{f}}{2 b+e}$, which, given the above definitions, is simplified to: $q_{f}=\frac{a-d-b k q_{\mathrm{car}}}{b+e+b j}$.

The representative $k$-firm maximizes its profits, $\pi_{c a r}=$ $\left(a-b\left(\frac{a-d-b k q_{c a r}}{b+e+b j} j+k q_{c a r}\right)\right) q_{c a r}-d q_{c a r}-\frac{e q_{c a r}^{2}}{2}$, which leads to its optimal production,

$$
q_{c a r}=\frac{(a-d)(b+e)}{e^{2}+2 b^{2} k+b e(1+j+2 k)} .
$$

Given (2.1), the production of the $j$-firm is

$$
q_{f}=\frac{a-d-\frac{b(a-d)(b+e) k}{e^{2}+2 b^{2} k+b e(1+j+2 k)}}{b+e+b j} .
$$

\footnotetext{
1 I have also worked with the direct demand and its respective residual demand. Moreover, in numerical estimates, despite the fact that the parameters are consistent, $b=1 / \beta, a=\alpha / \beta$, the firms' profits, quantities and price were not identical, precisely as other researchers warned.
} 
Multiplying (2.1) with $k$ and (2.2) with $j$ and sum we get the total $Q$. The price is then found to be:

$$
\begin{aligned}
& P_{c a r}=a-b Q \\
& =\frac{a(b+e)\left(e^{2}+b^{2} k+b e(1+j+k)\right)+b d\left(e^{2}(j+k)+b e(1+j)(j+2 k)+b^{2}(k+2 j k)\right)}{(b+e+b j)\left(e^{2}+2 b^{2} k+b e(1+j+2 k)\right)} .
\end{aligned}
$$

Finally, the individual profits are:

$$
\begin{aligned}
& \pi_{c a r}=\frac{(a-d)^{2}(b+e)^{2}}{2(b+e+b j)\left(e^{2}+2 b^{2} k+b e(1+j+2 k)\right)} \\
& \pi_{f}=\frac{(a-d)^{2}(2 b+e)\left(e^{2}+b^{2} k+b e(1+j+k)\right)^{2}}{2(b+e+b j)^{2}\left(e^{2}+2 b^{2} k+b e(1+j+2 k)\right)^{2}}
\end{aligned}
$$

In accordance with model 1, these formulae can be used for perfect competition (if $k=0$ ) or perfect cartel (if $j=0$ ).

Notice that all referred researchers do not use $j$, but $n$ and $k$ instead, and their derived formulae are modified. Moreover, since I have also worked with dynamic graphs and tables, it was more convenient to keep both $j$ and $k$ in all formulae, where as I mentioned previously, $j=n-k$.

\section{Internal and External Stability}

As is known, a cartel is internally stable if a $k$-firm has no profit incentives to become fringe. Similarly, a cartel is externally stable if it is not profitable for a $j$-firm to join the cartel. More specifically, the profit improvement by shifting group membership must be investigated ex-post and not ex-ante. For instance, if currently the $j$-firm has a higher profit than the $k$-firm and remains fringe, such a shortsighted decision is not necessary correct. The relevant incentive is to compare the current profit as a fringe, versus the cartel profit after it joined the cartel.

As was mentioned earlier, all researchers, including Konishi and Lin (1999) and $\mathrm{Zu}$ et al. (2012) who conducted numerical simulations, attempted to derive general conditions for internal and external stability, based on simplified profit functions like those above.

In model 1, the profit functions (1.4) and (1.5) are simpler to investigate. It is easy to show that with any plausible parameter values and any $\{k, j\} \in$ Integers, $\pi_{f r} \leq \pi_{\text {cart }}$ is always false. Since ex-ante, no $j$-firm has any incentive to join the cartel, all firms, apart from the lower bound to define a cartel, $k \geq 2$, would prefer to remain fringe. Moreover, the external stability will simply depend upon how many $k$-firms will find it profitable to exit. Consequently, the relevant problem is to find the internal stability.

I started first running a number of simulations, based on the following parameters $\{\alpha=1000, \beta=20, d=10, e=1\}$, and various number of firms shifting from one group to another. Figure 1 shows the profits, the individual and total production, as 


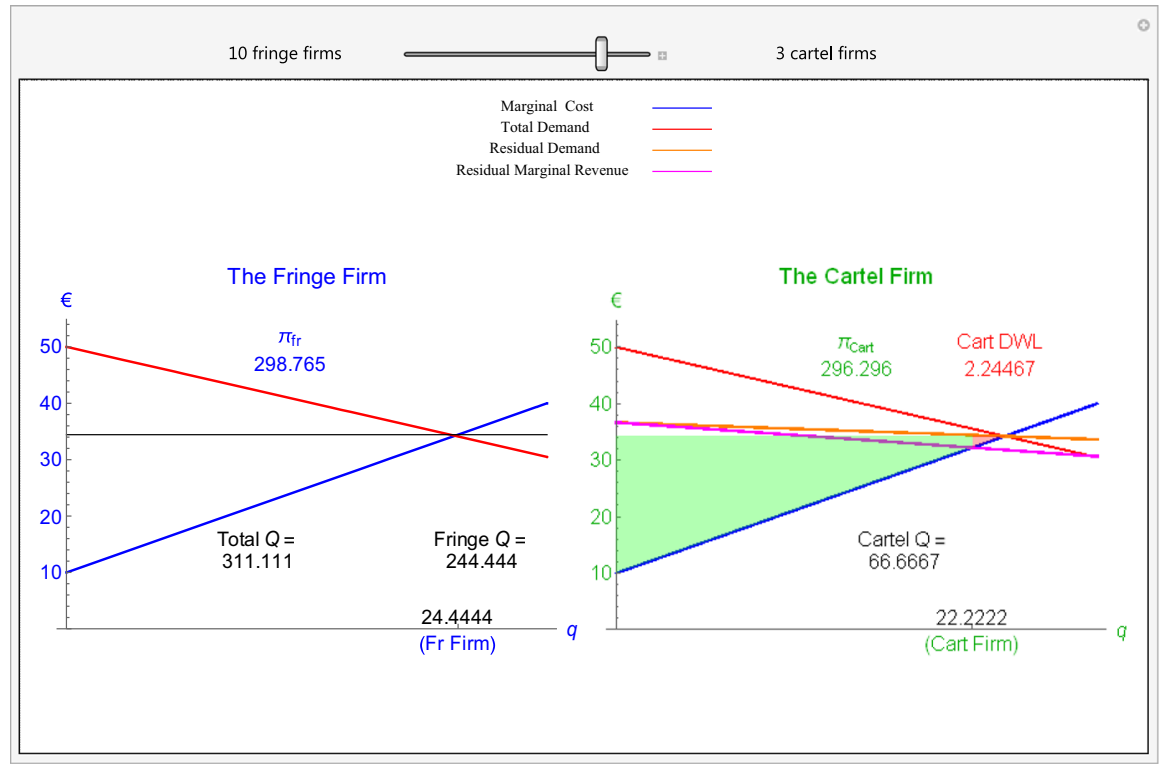

Fig. 1 Stable cartel (Model 1); $\{\alpha=1000, \beta=20, \mathrm{~d}=10, e=1, j+k=13\}$

well as the dead weight losses from cartel, with $n=j+k=13$. The internal stability is obtained with $k=3, j=10$, where the $j$-firm makes a higher profit (298.765) compared to the $k$-firm (296.296) and produces more (24.44 vs. 22.22). If one $k$-firm exits, ${ }^{2}$ as a fringe will make a lower profit, (296.018), and therefore would prefer to stay in cartel. Similarly, if we start with $k=2, j=11$, one fringe would join the cartel and will increase its profit by $(296.296-296.018)$. Thus, while a particular $j$-firm (like Norway in the OPEC case) wouldn't like to join the cartel when $k=3$, it would welcome if another $j$-firm (like Russia) did it! Still, it wouldn't work because one of the $k$-firms (like Iran) would find profitable to exit.

In model 2, the profit functions (2.4) and (2.5) are more complicated. With plausible parameter values and any $\{k, j\} \in$ Integers, both $\pi_{f} \leq \pi_{c a r}$ and $\pi_{f}>\pi_{c a r}$ are possible. Figure 2 shows the profits, the individual and total production with nine firms. ${ }^{3}$ The internal and external stability in this case, is obtained with $k=4, j=5$.

Before we turn to the appropriate formulation of internal and external stability, we can investigate the profits, quantities, prices the sum of consumer surplus and the welfare (W) for both models in Table $1,{ }^{4}$ for various combinations of $j$ -

\footnotetext{
2 This is a dynamic graph, programmed in Mathematica, using its function "Manipulate". All interesting values and curves change when one scrolls left or right the number of fringe/cartel firms. The code and the graph is available at a request, or found in Papahristodoulou (2014). In order to see how all estimates change, you need to download the Mathematica player from http://www.wolframalpha.com/pro/downloadcdf-player.html?src=callout.

3 The code and the dynamic graph is also available at a request.

4 This is based on a dynamic table, programmed in Mathematica, and available at a request as well. All values are calculated with very high precision.
} 


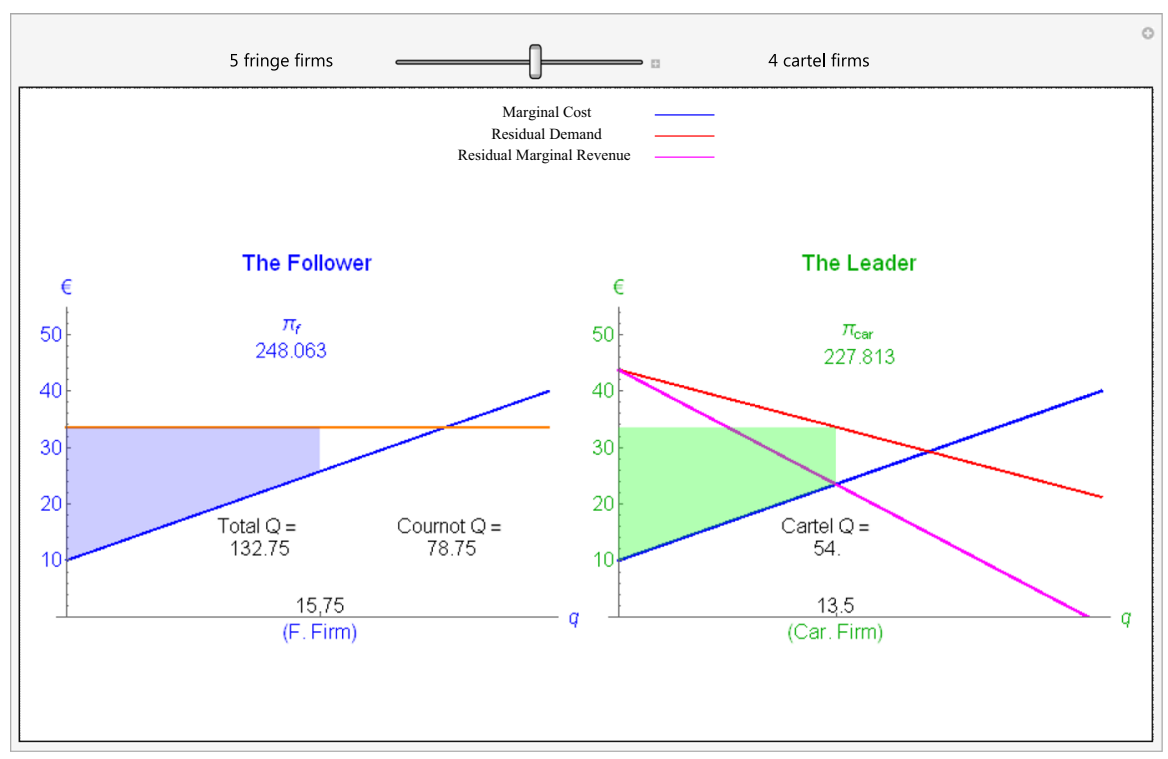

Fig. 2 Stable cartel (Model 2); $\{\mathrm{d}=10, e=1, a=100, b=0.5, j+k=9\}$

and $k$-firms and parameters. There are two sets of firms, $\{n=15 \& n=12\}$, and two sets of parameters, $\{\alpha=1000, \beta=20, d=10, e=1 ; a=100, b=0.5\}$ and $\{\alpha=800, \beta=25, d=10, e=1.2 ; a=80, b=0.4\}$, applied to both models.

Let us check the internal stability in model 1 , with $n=12$ and the first set of parameters (top right). If we start with $k=5, j=7$, and follow the arrow to the left, one $k$ - firm has incentive to join the fringe and gain an additional profit of $322.5-320.32$. Also, with $k=4, j=8$, one more $k$ - firm will join the fringe group and gain an additional profit of 318.07-317.46. With $k=3, j=9$, no $k$-firm will exit, because as a cartel firm it makes a profit equal to 315.27 , compared to 314.96 it would make being the 10 th fringe. Thus, the cartel is internally stable with $k=3, j=9$.

It is also externally stable there, if for instance we start with $k=2, j=10$ and follow the arrow to the right. One $j$-firm has an incentive to join the cartel, despite the fact that it has a higher profit ex-ante, i.e. $\left(\pi_{\mathrm{fr}(10,2)}=314.96>\pi_{\mathrm{cart}(10,2)}=313.725\right)$. By joining the cartel, its ex-post profit will be slightly higher, 315.27>314.96.

A similar argument applies with $n=15$ (top left), as well as with the second set of parameters. It is clear from Table 1 that the internal and external stability in model 1 always consists of three $k$-firms (highlighted profits), even if the number of firms and the parameter values change. The intuition behind that is as follows. With two $k$-firms, the total production and the production from the $j$-firms, is rather big leading to a low cartel price and lower profits to both type of firms. With three $k$-firms, the total production is lower, leading to a higher price and profits. The $j$-firms are benefited more because they increase their own production, while the $k$-firms reduce theirs. The same effects appear with more than three $k$-firms. But, when the actual profit gap between the fringe and the cartel firms widens (such as when $k=4, j=8$ ), one $k$-firm will have an incentive to join the $\mathrm{j}$-firms, produce more and increase its profit as a 
Table 1 Key findings with $j$ - and $k$-firms, $n=15$ and $n=12$

\begin{tabular}{|c|c|c|c|c|c|c|c|c|c|}
\hline & & $\begin{array}{l}k=2, \\
j=13\end{array}$ & $\begin{array}{l}k=3, \\
j=12\end{array}$ & $\begin{array}{l}k=4, \\
j=11\end{array}$ & $\begin{array}{l}k=5, \\
j=10\end{array}$ & $\begin{array}{l}k=2, \\
j=10\end{array}$ & $\begin{array}{c}k=3, \\
j=9\end{array}$ & $\begin{array}{c}k=4, \\
j=8\end{array}$ & $\begin{array}{c}k=5, \\
j=7\end{array}$ \\
\hline & & & $\alpha$ & $1000 ; \beta$ & $3=20$ & $=10 ; e$ & $=1$ & & \\
\hline \multirow{19}{*}{$\begin{array}{l}\frac{3}{0} \\
\frac{1}{0} \\
\frac{2}{0}\end{array}$} & $\pi_{f r}$ & 262.94 & 265.11 & 268.18 & 272.22 & 314.96 & 318.07 & 322.5 & 328.34 \\
\hline & $\pi_{\text {cart }}$ & 262.08 & 263.16 & 264.68 & 266.67 & 313.73 & 315.27 & 317.46 & 320.32 \\
\hline & $P_{\text {cart }}$ & 32.932 & 33.026 & 33.159 & 33.333 & 35.098 & 35.222 & 35.397 & 35.626 \\
\hline & $q_{f r}$ & 22.932 & 23.026 & 23.159 & 23.333 & 25.098 & 25.222 & 25.397 & 25.626 \\
\hline & $q_{\text {cart }}$ & 21.622 & 21.053 & 20.513 & 20.0 & 23.529 & 22.857 & 22.222 & 21.622 \\
\hline & $Q_{\text {tot }}$ & 341.36 & 339.47 & 336.81 & 333.33 & 298.04 & 295.57 & 292.06 & 287.49 \\
\hline & $\Sigma \pi$ & 3942.37 & 3970.74 & 4008.75 & 4055.56 & 3777.01 & 3808.41 & 3849.84 & 3899.96 \\
\hline & $\Sigma C S$ & 2913.15 & 2881.06 & 2835.98 & 2777.78 & 2220.68 & 2183.99 & 2132.52 & 2066.22 \\
\hline & $W$ & 6855.52 & 6851.8 & 6844.73 & 6833.33 & 5997.69 & 5992.4 & 5982.36 & 5966.18 \\
\hline & \multicolumn{9}{|c|}{$\alpha=800 ; \beta=25 ; d=10 ; e=1.2$} \\
\hline & $\pi_{f r}$ & 107.09 & 107.62 & 108.37 & 109.35 & 123.01 & 123.71 & 124.70 & 125.99 \\
\hline & $\pi_{\text {cart }}$ & 106.88 & 107.14 & 107.52 & 108.0 & 122.73 & 123.08 & 123.57 & 124.21 \\
\hline & $P_{\text {cart }}$ & 24.636 & 24.643 & 24.664 & 24.7 & 25.682 & 25.692 & 25.721 & 25.768 \\
\hline & $q_{f r}$ & 13.359 & 13.393 & 13.495 & 13.5 & 14.318 & 14.359 & 14.416 & 14.491 \\
\hline & $q_{\text {cart }}$ & 12.766 & 12.5 & 12.245 & 12.0 & 13.634 & 13.333 & 13.044 & 12.766 \\
\hline & $Q_{\text {tot }}$ & 199.21 & 198.21 & 196.81 & 195.0 & 170.45 & 169.23 & 167.51 & 165.27 \\
\hline & $\Sigma \pi$ & 1605.92 & 1612.88 & 1622.16 & 1633.5 & 1475.52 & 1482.6 & 1491.89 & 1503.01 \\
\hline & $\Sigma C S$ & 733.45 & 729.15 & 721.92 & 711.75 & 538.48 & 533.75 & 525.90 & 515 \\
\hline & $W$ & 2339.37 & 2342.03 & 2344.08 & 2345.25 & 2014 & 2016.33 & 2017.79 & 2018.01 \\
\hline & & & & $t=100 ; b$ & $0=0.5 ; a$ & $=10 ; e=$ & & & \\
\hline \multirow{19}{*}{$\begin{array}{l}3 \\
\frac{3}{0} \\
\frac{2}{0} \\
\frac{0}{n}\end{array}$} & $\pi_{f}$ & 94.399 & 95.063 & 97.814 & $102.77^{*}$ & 135.95 & 138.90 & 146.29 & 158.76 \\
\hline & $\pi_{c}$ & 103.55 & 101.25 & 100.14 & 100.14 & 147.57 & 144.64 & 144.07 & 145.8 \\
\hline & $P_{\text {car }}$ & 24.574 & 24.63 & 24.84 & 25.206 & 27.489 & 27.678 & 28.142 & 28.9 \\
\hline & $q_{f}$ & 9.716 & 9.75 & 9.89 & 10.134 & 11.659 & 11.786 & 12.095 & 12.6 \\
\hline & $q_{\text {car }}$ & 12.273 & 11.25 & 10.385 & 9.643 & 14.211 & 12.857 & 11.739 & 10.8 \\
\hline & $Q_{\text {tot }}$ & 150.85 & 150.75 & 150.33 & 149.59 & 145.02 & 144.64 & 143.72 & 142.2 \\
\hline & $\Sigma \pi$ & 1434.29 & 1444.5 & 1476.51 & 1528.35 & 1654.68 & 1684.06 & 1746.57 & 1840.32 \\
\hline & $\Sigma C S$ & 5689.1 & 5681.39 & 5649.75 & 5594.14 & 5257.72 & 5230.39 & 5163.53 & 5055.21 \\
\hline & $W$ & 7123.39 & 7125.89 & 7126.26 & 7122.48 & 6912.4 & 6914.45 & 6910.1 & 6895.53 \\
\hline & \multicolumn{9}{|c|}{$a=80 ; b=0.4 ; d=10 ; e=1.2$} \\
\hline & $\pi_{f}$ & 82.174 & 83.076 & 85.422 & 89.325 & 116.12 & 118.75 & 124.37 & 133.41 \\
\hline & $\pi_{c}$ & 86.040 & 85.069 & 84.848 & 85.366 & 120.69 & 119.66 & 120.09 & 122.04 \\
\hline & $P_{c a r}$ & 24.504 & 24.583 & 24.788 & 25.122 & 27.241 & 27.436 & 27.843 & 28.481 \\
\hline & $q_{f}$ & 9.065 & 9.115 & 9.242 & 9.451 & 10.776 & 10.897 & 11.152 & 11.550 \\
\hline & $q_{c a r}$ & 10.448 & 9.722 & 9.091 & 8.537 & 12.069 & 11.111 & 10.294 & 9.589 \\
\hline & $Q_{\text {tot }}$ & 138.74 & 138.54 & 138.03 & 137.20 & 131.90 & 131.41 & 130.39 & 128.80 \\
\hline & $\Sigma \pi$ & 1240.34 & 1252.12 & 1279.04 & 1320.08 & 1402.57 & 1427.76 & 1475.32 & 1544.1 \\
\hline & $\Sigma C S$ & 3849.76 & 3838.76 & 3810.47 & 3764.5 & 3479.34 & 3453.73 & 3400.42 & 3317.8 \\
\hline & $W$ & 5090.1 & 5090.88 & 5089.51 & 5084.59 & 4881.91 & 4881.49 & 4875.74 & 4861.9 \\
\hline
\end{tabular}

$j$-firm. Other studies, see for example Prokop (1999), find a similar stability, when their cost parameter is equal to unit. The fact that $e \geq 1$ does not affect the optimal number of $k$-firms, makes this finding stronger. Thus, the first proposition is:

Proposition 1 Given the above parameters, as well $e \geq 1$, for any $n \geq 3$, internal stability in model 1, is always achieved when $k=3$. 
On the other hand, the optimal number of cartel firms in model 2 varies (highlighted). For instance, in three cases, i.e. with $n=12$, and both sets of parameters and with $n=15$ with the second set of parameters, we find $k=4$. With $n=15$ and the first set of parameters, the cartel stability consists of $k=5$. As before, the cartel stability is proved simply if we follow the direction of the arrows. Notice that there is no arrow in the star marked follower profit value 102.77. Moreover, if we started with $k=6, j=9$, the ex-ante profits would be: $\pi_{f(9,6)}=110.25>\pi_{c a r(9,6)}=101.25$. Thus, one $k$-firm would join the group of followers, leading to externally and internally stable cartel, where $\pi_{f(10,5)}=102.77>\pi_{\operatorname{car}(10,5)}=100.14$. This finding is consistent with Shaffer's (1995) proposition 5, namely that "profits of each firm in a stable cartel are less than those of an associated Cournot $j$-firm, for any $n>1$, even or odd".

Three more points are worth to mention from Table 1 .

First, as expected, in both models, irrespectively if the cartel is stable or not prices increase with more $k$-firms, $\frac{\partial P_{\text {cart }}}{\partial k}>0, \frac{\partial P_{\text {car }}}{\partial k}>0$.

Second, in model 1 , the $j$-firms always produce more than the $k$-firms. On the other hand, in model 2 , the $j$-firm produces more than the $k$-firm, only when $k \geq k^{*}$, where $k^{*}$ is the implied optimal number of $k$-firms.

Third, in model 1, as expected, the total consumer surplus, $(\Sigma C S)$, and the value of welfare $(W)$ is higher with more $j$-firms, with the first set of parameters. On the other hand, a relatively higher share of $k$-firms yields higher welfare with the second set of parameters. Moreover, in model 2, the value of welfare is higher with $k^{*}>k \geq 2$. For instance, with $n=15,(a=100, b=0.5, d=10, e=1)$, the cartel stability consists of $k^{*}=5$, while the welfare is maximized with $k=4$. This is an interesting finding and should be taken into consideration by policy makers, if the goal is to maximize the welfare from an imperfect cartel.

\section{Internal and External Stability Formulation}

In this section I will formulate the internal and external stability for model 2. Similar formulations apply for the simpler model 1 .

From the numerical example above we conclude that the $k$-firm will remain in cartel, if the after exit profit as a follower firm, $\pi_{f(j+1, k-1)}$, is lower than the existing profit as a $k$-firm, $\pi_{c a r(j, k)}$. Similarly, it will leave the cartel if $\pi_{f(j+1, k-1)} \geq \pi_{\operatorname{car}(j, k)}$. Thus, the problem for the $k$-firm is to find out: (i) how much lower the $\pi_{f(j+1, k-1)}$ will be after it decided to defect to the followers; (ii) which is the unknown threshold cartel profit $\pi *_{\operatorname{car}(j, k)}$, to be compared with the follower's profit. In order to simplify the notation, let us assume $k+j=25$ and $e=2$.

The internal stability is formulated as follows.

First of all we need to identify a $k$ - and a $j$-firm from all $\{k, j\}$ integer combinations, and compare their profits. Obviously, when we solve the problem sequentially, starting with $k+j=3$ and increasing it with one more firm at a time, the previous $k$-value can be set as a lower bound. The upper bound should include a few more $k$-firms (normally $k+1$ will be sufficient). With these bounds, there would be only a few $\{k, j\}$ integer combinations, and the solution will be speeded up. We therefore need some binary variables that will ensure the consistency of appropriate profits with the appropriate $\{k, j\}$ integer combination. 
Second, since a $k$-firm will join the group of followers only if it is profitable, we need to minimize $\pi_{f}-\pi_{c a r}$, subject to Shaffer's proposition, namely $\pi_{f}-\pi_{c a r}>0$. Notice that if Shaffer's strict inequality was formulated as $\pi_{f}-\pi_{c a r} \geq 0$, we could obtain a suboptimal solution, where both profits are equal and lower compared to some other pre-exit $\pi_{c a r}$. Since we do not know which $\pi_{c a r}$ in objective function to compare with, we multiply each potential profit with its respective binary, where only one of them is equal to unit.

The previous optimal solution with $n=24$, is attained with $k=5, j=19$. Consequently with $n=25$, we need to consider two potential profits, one with $k=5, j=20$ and another with $k=6, j=19$, and two binaries as well. The bounds of $\{k, j\}$ integer combinations are obviously consistent with the same binaries too. Notice that only one of the following key constraints below is binding:

$$
\pi_{c a r}-\pi_{f} y_{1}+\pi_{f}-\pi_{c a r} y_{1} \geq 0, \pi_{c a r}-\pi_{f} y_{2}+\pi_{f}-\pi_{c a r} y_{2} \geq 0 .
$$

If $y_{1}=0$, neither $k=5$, nor $j=20$. Since $y_{2}=1$, the optimal solution is $k=6, j=19$. In this case, the first constraint is reduced to $\pi_{c a r}+\pi_{f}>0$, which is always true, while the second constraint is equal to zero. Similarly, if $y_{1}=1$, then $y_{2}=0$, i.e. the second constraint is again reduced to $\pi_{c a r}+\pi_{f}>0$, while the first constraint is equal to zero. Hence, the model is:

$$
\begin{aligned}
& \text { NMinimize }\left[\left\{\pi_{f}-\pi_{\text {car }} y_{1}-\pi_{c a r} y_{2},\right.\right. \\
& \pi_{f}-\pi_{c a r}>0, \pi_{c a r}-\pi_{f} y_{1}+\pi_{f}-\pi_{\text {car }} y_{1} \geq 0, \pi_{c a r}-\pi_{f} y_{2}+\pi_{f}-\pi_{c a r} y_{2} \geq 0, \\
& 1 \geq\left\{y_{1}, y_{2}\right\} \geq 0, y_{1}+y_{2}=1, j \geq 19, k \geq 5, k+j=25, k \geq 5 y_{1}, k \geq 6 y_{2}, \\
& \left.\left.j \geq 20 y_{1}, j \geq 19 y_{2},\left\{k, j, y_{1}, y_{2}\right\} \in \text { Integers }\right\},\left\{k, j, y_{1}, y_{2}\right\}\right]
\end{aligned}
$$

Using the following parameters $\{a=100, d=10, b=0.5, e=\{1,2,3\}\}$, the respective profits in model 2 (with $e=2$ ), are:

$$
\pi_{f}=\frac{48600(5+j+1.25 k)^{2}}{(5+j)^{2}(5+j+2.5 k)^{2}}, \quad \pi_{c a r}=\frac{50625}{(5+j)(5+j+2.5 k)} .
$$

The global solution is found at $k=6, j=19, y_{2}=1, \min =0.9569$. And as I mentioned above, if Shaffer's condition is formulated as $\pi_{f}-\pi_{c a r} \geq 0$, we obtain a suboptimal solution, with $k=5, j=20, y_{1}=1$, $\min =0$, where $\pi_{f(5,20)}=\pi_{\operatorname{car}(5,20)}=54$. In that case, both profits are lower compared to the global solution, $\left(\pi_{f(6,19)}>\pi_{c a r(6,19)}\right)=$ $(55.0435>54.0865)$.

Similarly, the external stability is formulated as:

$$
\begin{aligned}
& \text { NMinimize }\left[\left\{\pi_{c a r}-\pi_{f} y_{1}-\pi_{f} y_{2},\right.\right. \\
& \pi_{c a r} \geq 0, \pi_{f}-\pi_{c a r} y_{1}+\pi_{c a r}-\pi_{f} y_{1} \geq 0, \pi_{f}-\pi_{c a r} y_{2}+\pi_{c a r}-\pi_{f} y_{2} \geq 0, \\
& 1 \geq\left\{y_{1}, y_{2}\right\} \geq 0, y_{1}+y_{2}=1, j \geq 19, k \geq 5, k+j=25, k \geq 6 y_{1}, k \geq 5 y_{2}, \\
& \left.\left.j \geq 19 y_{1}, j \geq 20 y_{2},\left\{k, j, y_{1}, y_{2}\right\} \in \text { Integers }\right\},\left\{k, j, y_{1}, y_{2}\right\}\right]
\end{aligned}
$$


Notice that in this case, it is sufficient to assume $\pi_{c a r} \geq 0$. The solution is the same, $k=6, j=19, y_{1}=1, \min =-0.9569$. The solution remains unchanged even if we keep the same constraint $\pi_{f}-\pi_{c a r}>0$ as in internal stability formulation.

\section{Comparing the Models}

Table 2 summarizes the internal and external stability for $k$-firms in model 2 and compares the estimates to those found by Konishi and Lin (1999) and Zu et al. (2012).

Despite the fact that we set $b=0.5$, instead of 1 as Konishi and Lin (1999), Zu et al. (2012) assume, our $k$-firms are almost identical to their estimates, when there are not more than ten firms in the market, especially when $e=3$. On the other hand, when $n \geq 11$, we find stable cartels consisting of lower number of $k$-firms compared to these studies. For instance, with $n=31$ and $e=1$, we find $9 / 31$, respectively $5 / 31 k$-firms with $e=3$, while they find $12 / 31$ and 8/31. Finally, my estimates are much lower than Shaffer (1995) and Escrihuela-Villar (2008), as implied by their proposed conditions.

In star marked cases of external stability, the local optimal solution would, erroneously, include one additional $j$-firm. For instance, with $n=8$ and $e=1$, the local optimum is obtained with $k=3, j=5$, because the profits there would be $\pi_{f}=273.71$ and $\pi_{c a r}=268$. A shortsighted $j$-firm would not join the cartel, as it currently makes higher profit. A wise $j$-firm though, would join the cartel, because with $k=4, j=4$, its cartel ex-post profit (274.06), would be higher than its ex ante profit (273.71), as a follower. The applied model is therefore global, and in this particular case, the objective function finds a $\min =274.06-309.55=-35.49$.

Contrary to Shaffer (1995), who argues that the new firm in the market will not join the cartel if we start from odd firms, and it will always join the cartel and if we start from even firms, my estimates show that the number of $k$-firms remains relatively stable when a few new firms entering the market. Irrespectively if we start from odd or even firms, a few more new firms always join the group of followers. When sufficiently enough new firms became followers, one more new firm would join the cartel. This is consistent with D'Aspremont et al. (1983) who find that when the number of firms in the market increase, the relative size of cartel firms decreases.

It appears that when researchers try to find optimal conditions for cartel stability, they do not find global optima, simply because by setting $b=1$, that parameter will be invisible in their profit formulae. In addition to that, the problem might not be formulated accurately. Consequently, the simplified proposed conditions can lead to incorrect $k$-size. Check for instance, that the incorrect (or unstable) optimum $k=3, j$ $=5$ would be found, if the external stability is formulated simpler (and wrong) as:

NMinimize[ $\left\{\pi_{c a r}, \pi_{c a r}-\pi_{f} \leq 0, \pi_{c a r} \geq 0, j \geq 1, k \geq 2, k+j=8,\{j \mid k) \in\right.$ Integers $\left.\},\{k, j\}\right]$

Similarly, the simplified Konishi and Lin (1999) condition would be obtained, if we modify the profit formulae (2.4) and (2.5) by assuming $j=n-k$, formulate it as above and apply the Mathematica function "Reduce". The conditions provided by Mathematica in this case are: 


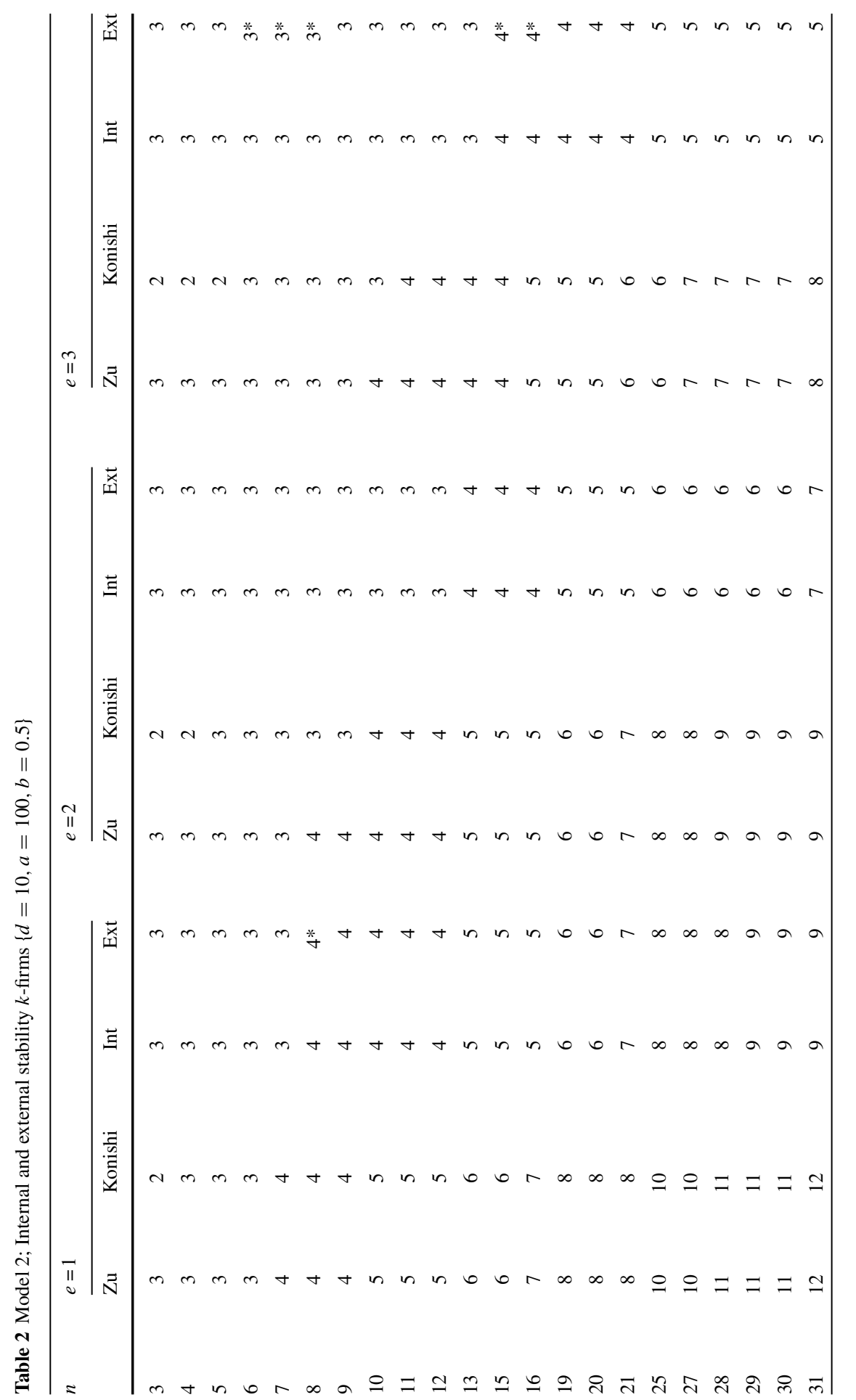




$$
\left(2<n \& 2 \leq k \& n \leq 3+\frac{e}{b}\right) \|\left(n>3+\frac{e}{b} \& \frac{b+e+b n}{2 b+e} \leq k\right)
$$

If we set $b=1$, we obtain the Konishi and Lin condition. Still, using $e=1$, with $n=10$, the formula gives $4 \leq k$, and not 5 as they report in their paper. ${ }^{5}$ If we set instead $b=0.5$, the formula gives $3.25 \leq k$, which is nearer 4 , i.e. the reported global optimum in Table 2.

Using the Konishi and Lin parameters , $(d=0, b=1)$, a correct "Reduce" formulation would be:

$$
\begin{aligned}
& \text { Reduce }\left[\left\{\pi_{f}-\pi_{c a r} y_{1}-\pi_{c a r} y_{2},\right.\right. \\
& \pi_{c a r}-\pi_{f} y_{1}+\pi_{f}-\pi_{c a r} y_{1} \geq 0, \pi_{c a r}-\pi_{f} y_{2}+\pi_{f}-\pi_{c a r} y_{2} \geq 0, \\
& 1 \geq\left\{y_{1}, y_{2}\right\} \geq 0, y_{1}+y_{2}=1, a>0, e \geq 1, d=0, b=1, j+k=8, \\
& \left.\left.j \geq 2, k \geq 3, k \geq 3 y_{1}, k \geq 4 y_{2}, j \geq 5 y_{1}, j \geq 4 y_{2},\left\{k, j, y_{1}, y_{2}\right\} \in \text { Integers }\right\},\left\{k, j, y_{1}, y_{2}\right\}\right]
\end{aligned}
$$

It gives the same correct values of Table 2 , associated with the correct $e$-values, i.e.:

$$
\begin{gathered}
a>0 \&\left(\left(y_{1}=0 \& y_{2}=1 \& e \geq 1 \& k=4 \& j=4\right) \|\right. \\
\left.\left(y_{1}=1 \& y_{2}=0 \& 2 e \geq 3 \& k=3 \& j=5\right)\right)
\end{gathered}
$$

With general parameter bounds, Mathematica failed to find a general formula for the optimal number of $k$ - or $j$-firms, within $3 \mathrm{~h}$ of computing time. With semi-numeric values, it found an algebraic large output, often combined with some pure functions (\#). Thus, the second proposition is:

Proposition 2 There is no algebraic global condition to ensure cartel stability in model 2. All suggested conditions are weak, locally stable and valid for a small number of firms.

Finally, precisely as in other studies, the value of cost parameter $e$, is negatively related to the number of $k$-firms. For instance, with $k+j=9, e=1$, using the same parameters, at equilibrium, each one of the five followers makes a higher profit than each one of the four cartel firms, equal to 20.25. This profit difference is not high enough for one more $k$-firm to exit. On the other hand, when $e=3$, one more cartel firm will join the fringe, despite the fact that the ex-ante profit difference is now lower (16.26) than before.

\footnotetext{
5 Konishi and Lin admit though that their condition is an approximation of the true $k$-size, but they also state that "the size of the stable cartel"... "is the smallest integer that is greater than the critical value of $\mathrm{k}$ ". The critical (simplified) value they refer to is given by $\frac{1+e+n}{2+e}$, when we use our " $e$ " which is identical to their " $b$ ". But this is different from $\frac{b+e+b n}{2 b+e}$, unless $b=1$. Other researchers too, (Shaffer 1995), seem to draw an incorrect conclusion when they argue that the optimal number of $k$-firms is independent from other parameters (including $b$ ).
} 


\section{Conclusions and Policy Implications}

The objective of this paper was to find out optimal conditions to ensure cartel stability in imperfect cartel markets, where fringe and cartel firms compete with a homogenous product. The answer to that problem depends mainly on the model selected and secondly on the set and the values of parameters used.

In the classical cartel versus competitive price-takers fringe firms model 1 , our estimates show that stable cartels are always found with $k=3$, for any $n \geq 3$, in accordance with other studies. The cartel stability with three cartel firms, is unaffected even if the slope of marginal cost $(=e)$ is higher than unit. The only effect that $e \geq 1$ has, is simply to decrease the profits of both groups, and not joining the other group of firms.

In this model, the quantities and the profits of a $j$-firm are always higher than those of a $k$-firm, irrespectively if the cartel is stable or unstable. In addition, as expected, the lower the number of the $k$-firms, the higher the welfare.

In the Stackelberg leader cartel versus Cournot fringe followers' model 2, our estimates show that stable cartels will consist of a few more cartel firms, compared to model 1 and would be more appropriate for the OPEC cartel mentioned in the start. Moreover, the optimal number of $k$-firms we found, is lower compared to other studies. If the cost parameter $e$ increases in this model, it hurts the leader cartel more than the followers, leading to stable cartels with fewer firms. Contrary to other researchers who claim that the optimal cartel size can be expressed by some simple algebraic conditions, this study, aided by the powerful Mathematica functions, fails to obtain such conditions. Instead, based on some plausible parameters, it finds global optimal solutions.

Compared to model 1 , model 2 finds that a $k$-firm produces more and makes higher profits than a $j$-firm, if the number of $k$-firms is lower than the optimal number required for stable cartels. Regarding the welfare, allowing a few $k$-firms, is not a bad idea! For instance, with $n=15$ and some plausible parameters, stable cartels will consist of five or four $k$-firms. In case with five $k$-firms, it is better to detect just only one $k$-firm instead of two or three $k$-firms. Similarly in case with four $k$-firms because the welfare will be lower if two $k$-firms are detected, instead of only one.

The policy implications from these findings are interesting. First of all, since in both models at equilibrium, the $f$-firms make slightly higher profits than the $k$-firms, the public authorities might be deceived and concentrate their efforts on $j$-firms, assuming that they are the $k$-ones. The $j$-firms who are benefited from the cartel behavior, would obviously deny these allegations and the existence of cartel too. On the other hand, if they check the respective production they will identify the $k$-firms, because at equilibrium they produce less than the $j$-firms.

If the public authorities know under which model the $k$ - and $j$-firms compete, they might be more successful in detecting the cartel. In model 1, the best policy is either (i) to identify and punish at least one out of the three $k$-firms, or (ii) grant amnesty to one of them that decides to co-operate and becomes whistleblower. Perhaps, with policy (i), the cartel will continue with two firms, as unstable, and the welfare will improve. Obviously, if policy (ii) is applied and turns successful, the cartel will be banned and the welfare will be maximized. 
On the other hand, in model 2, things are different for two reasons. First, the optimal number of $k$-firms is often larger than in model 1 . Second, in terms of welfare, very small cartels with a couple of firms might be worse than cartels consisting of three or four firms. The optimal number of $k$-firms per se, is not a problem. On the contrary; with $n=15$ the probability of identifying a $k$-firm increases from $3 / 15$ in model 1 to $4 / 15$, or $5 / 15$, depending upon the parameters. The estimates suggest that, as long as the authorities managed to identify a $k$-firm, they should stop. It is not only difficult, expensive and time consuming to continue identifying and detecting all $k$-firms. The additional welfare gains are almost zero, and in some cases negative, compared to unstable cartels with four or three $k$-firms. The fact that these few remaining $k$-firms make higher profits compared to the $j$-firms should be irrelevant.

Acknowledgements The author thanks an anonymous referee for the comments and suggestions.

Open Access This article is distributed under the terms of the Creative Commons Attribution 4.0 International License (http://creativecommons.org/licenses/by/4.0/), which permits unrestricted use, distribution, and reproduction in any medium, provided you give appropriate credit to the original author(s) and the source, provide a link to the Creative Commons license, and indicate if changes were made.

\section{Compliance with Ethical Standards}

Conflict of interest The author declares that he has no conflict of interest.

\section{References}

Bos, I., \& Wandschneider, F. (2011). Cartel ringleaders and the corporate leniency program. Working paper, Center for Competition Policy, pp. 11-13.

Carlton, D. W., \& Perloff, J. M. (2015). Modern industrial organization (4th ed.). London: Pearson.

Clemens, G., \& Rau, H. A. (2014). Do leniency policies facilitate collusion? Experimental evidence. Working paper (130), Düsseldorf Institute for Competition Economics.

Daskin, A. J. (1989). Cartel stability in the price leadership model: Three-firm cartels and the role of implicit collusion. Discussion paper (17), Boston University School of Management.

D’Aspremont, C., Jacquemin, A., Gabszewicz, J. J., \& Weymark, J. A. (1983). On the stability of collusive price leadership. Canadian Journal of Economics, 16, 17-25.

Donsimoni, M. P., Economides, N., \& Polemarchakis, H. (1986). Stable cartels. International Economic Review, 27, 317-327.

Escrihuela-Villar, M. (2008). A note on cartel stability and endogenous sequencing with tacit collusion. Working paper, Universitat de les Illes Balears, Palma de Mallorca, Spain.

European Commision. (2017). http://ec.europa.eu/competition/cartels/overview/index_en.html.

Konishi, H., \& Lin, P. (1999). Stable cartels with a Cournot fringe in a symmetric oligopoly. KEIO Economic Studies, 36, 1-10.

OPEC. (2016). Annual statistical bulletin. https://www.opec.org/opec_web/static_files_project/media/ downloads/publications/ASB2016.pdf.

Papahristodoulou, C. (2014). Imperfect cartel: A mathematica demonstration. http://demonstrations. wolfram.com/ImperfectCartel/.

Prokop, J. (1999). Process of dominant cartel formation. International Journal of Industrial Organization, 17, 241-257.

Selten, R. (1973). A simple model of imperfect competition, where 4 are few and 6 are many. International Journal of Game Theory, 2(1), 141-201.

Shaffer, S. (1995). Stable cartels with a Cournot fringe. Southern Economic Journal, 61, 744-754.

Zu, L., Zhang, J., \& Wang, S. (2012). The size of stable cartels: An analytic approach. International Journal of Industrial Organization, 30, 217-222. 